\title{
Performance of the SRK/T formula using A-Scan ultrasound biometry after phacoemulsification in eyes with short and long axial lengths
}

Yunus Karabela ${ }^{1 *}$ (D) Mustafa Eliacik ${ }^{2}$ and Faruk Kaya ${ }^{1}$

\begin{abstract}
Background: The SRK/T formula is one of the third generation IOL calculation formulas. The purpose of this study was to evaluate the performance of the SRK $T$ formula in predicting a target refraction $\pm 1.0 \mathrm{D}$ in short and long eyes using ultrasound biometry after phacoemulsification.

Methods: The present study was a retrospective analysis, which included 38 eyes with an $\mathrm{AL}<22.0 \mathrm{~mm}$ (short $\mathrm{AL}$ ), and 62 eyes $\geq 24.6 \mathrm{~mm}$ (long AL) that underwent uncomplicated phacoemulsification. Preoperative AL was measured by ultrasound biometry and SRK/T formula was used for IOL calculation. Three different IOLs were implanted in the capsular bag. The prediction error was defined as the difference between the achieved postoperative refraction, and attempted predicted target refraction. Statistical analysis was performed with SPSS V21.

Results: In short ALs, the mean age was $65.13 \pm 9.49$ year, the mean AL was $21.55 \pm 0.45 \mathrm{~mm}$, the mean $\mathrm{K} 1$ and K2 were $45.76 \pm 1.77 \mathrm{D}$ and $46.09 \pm 1.61 \mathrm{D}$, the mean IOL power was $23.96 \pm 1.92 \mathrm{D}$, the mean attempted (predicted) value was $0.07 \pm 0.26 \mathrm{D}$, the mean achieved value was $0.07 \pm 0.63 \mathrm{D}$, the mean PE was $0.01 \pm 0.60 \mathrm{D}$, and the MAE was $0.51 \pm$ 0.31D. A significant positive relationship with $\mathrm{AL}$ and $\mathrm{K} 1, \mathrm{~K} 2, \mathrm{IOL}$ power and a strong negative relationship with PE and achieved postoperative was found. In long ALs, the mean age was $64.05 \pm 7.31$ year, the mean AL was $25.77 \pm 1$. $64 \mathrm{~mm}$, the mean $\mathrm{K} 1$ and $\mathrm{K} 2$ were $42.20 \pm 1.57 \mathrm{D}$ and $42.17 \pm 1.68 \mathrm{D}$, the mean IOL power was $15.79 \pm 5.17 \mathrm{D}$, the mean attempted value was $-0.434 \pm 0.315 \mathrm{D}$, the mean achieved value was $-0.42 \pm 0.96 \mathrm{D}$, the mean PE was $-0.004 \pm 0.93 \mathrm{D}$, the MAE was $0.68 \pm 0.62 \mathrm{D}$. A significant positive relationship with $\mathrm{AL}$ and $\mathrm{K} 1, \mathrm{~K} 2$ and a significant positive relationship with PE and achieved value, otherwise a negative relationship with $\mathrm{AL}$ and IOL power was found. There was a little tendency towards hyperopic for short ALs and myopic for long ALs. The majority of eyes (94.74 \%) for short ALs and (70.97\%) for long ALs were within $\pm 1 \mathrm{D}$ of the predicted refractive error. No significant relationship with PE and IOL types, AL, K1, K2, IOL power, and attempted value, besides with MAE and AL, K1, K2, age, attempted, achieved value were found in both groups.
\end{abstract}

Conclusion: The SRK/T formula performs well and shows good predictability in eyes with short and long axial lengths. Keywords: IOL power calculation, SRK/T, Refractive outcome, Short axial length, Long axial length, Cataract surgery

\footnotetext{
*Correspondence: mrsbela@yahoo.com

${ }^{1}$ Department of Ophthalmology, Istanbul Medipol University, Esenler

Hospital, Birlik Mah., Bahceler Cad., Number 5, Esenler, Istanbul 34230, Turkey

Full list of author information is available at the end of the article
} 


\section{Background}

Cataract surgery is the most frequently performed ophthalmic surgery in the world. With the advanced technology and improvement in surgical techniques, final refractive outcomes and patient satisfaction are essential for determining the success of this procedure [1]. To achieve optimum outcomes, preoperative biometry must be accurate and an accurate IOL power (IOLp) formula must be used [2].

Intraocular lens (IOL) power calculation formulas have been evolving since 1949 when Harold Ridley implanted the first IOL into a human eye [3]. Various theoretical and regression formula are available for calculation of IOL power. Holladay 1 [4], Hoffer Q [5], and SRK-T [6] are known as third generation formulas and Holladay 2 [7], Haigis [8], Olsen [9] as fourth or newer generation formulas. Although third and fourth generation formulas are well accurate in eyes with average axial length, there is no general consensus as to which formula for IOL measurement is the most accurate in short or long eyes [1, 4-9].

Retzlaff JA, Sanders DR, and Kraff MC developed the SRK/T formula in 1990. The SRK/T (T for theoretical) is a formula, representing a combination of linear regression method with a theoretical eye model [6].

Ultrasound (US) biometry (A-Scan) and partial coherence interferometer (PCI)-based devices are the most commonly used methods for determining IOL power [10]. Previous comparisons of ultrasound biometry and optical biometry were reported equal or better results with optical biometry. However, ultrasound biometry remains the preferred method of measuring the axial length in the most practices, especially in developing countries or dense ocular media or inadequate measurements of PCI-based device [10-16].

The purpose of this study is to evaluate the performance of the SRK/T formula using contact ultrasound biometry in predicting a target postoperative refraction $\pm 1.0 \mathrm{D}$ in eyes with short and long AL after phacoemulsification and foldable lens implantation.

\section{Methods}

The records of all patients who had uncomplicated phacoemulsification with implantation of foldable IOL in the capsular bag between 2006 and 2012 at the Nisa Hospital, Istanbul, Turkey, were retrospectively reviewed. Patients were divided into 2 groups based on $\mathrm{AL}<22.00 \mathrm{~mm}$ (Group1, short ALs), and $\geq 24.6 \mathrm{~mm}$ (Group2, long ALs). Phacoemulsification was performed using Sovereign Compact Cataract Extraction System (Abbott Medical Optics Inc., Illionis, USA) and the foldable IOL was implanted in the capsular bag, through a $3.0-3.5 \mathrm{~mm}$ clear corneal incision by a single surgeon (YK). Three types of IOLs were used in this present study; Softec 1(Lenstec Inc., St. Petersburg, FL, USA), DrSchmidt
(HumanOptics AG, Erlangen, Germany), Acriva (VSY, Istanbul,Turkey). Patients with intraoperative and postoperative complications, pre-existing astigmatism $>2.5 \mathrm{D}$, history of previous ocular surgery or injury, and presence of associated ocular pathologies, monocular patients, patients in whom IOL power was calculated with other formulas, patients with incomplete pre or postoperative data were excluded.

Preoperatively, all patients underwent a full ophthalmological examination including uncorrected and bestcorrected Snellen visual acuity, intraocular pressure (IOP), slit-lamp and fundus examination, biometry for IOL power calculation including keratometry, and AL measurements. Refraction and keratometry were carried out by using the autokerato-refractometer (Topcon KR 8000, Japan). The axial length was measured by the contact method using AScan ultrasonic biometer (EZ AB5500+ A-Scan/B-Scan; Sonomed Inc., Lake Success, NY, USA). The SRK/T formula was chosen to predict the IOL power. The manufacturers' recommended A-constants were used for the IOL type. The surgeon's goal in IOL power selection was a lens power that would yield a postoperative refraction $\pm 1.0 \mathrm{D}$ accurate. All patients were evaluated on postoperative days 1, 7 and 30. The final refraction carried out with the autokerato-refractometer at 30 days postoperatively and confirmed by subjective refraction. All records of the refraction were converted into a spherical equivalent value, which was taken as the refractive outcome. Postoperative refractive prediction errors, mean PE and MAE were calculated for all patients.

The retrospective study was approved by the Ethics Committee of the Istanbul Medipol University, and was conducted in accordance with the tenets of the Declaration of Helsinki by obtaining written informed consent from all patients.

\section{Statistical analysis}

Statistical analysis was conducted using SPSS software (21.0, SPSS Inc., Chicago, IL, USA). Values were recorded as mean $\pm \mathrm{SD}$ (standard deviation). A test of the normality of the data distribution was performed using the Shapiro-Wilk tests. The correlation between prediction error(PE) and $\mathrm{AL}, \mathrm{K} 1, \mathrm{~K} 2$, IOL power and age of the patient was made using the Pearson's and Sperman's rank correlation coefficient depending on the normality of the data. In all cases, a $p$-value less than 0.05 were considered statistically significant. Paired Samples $t$ test was used for difference between attempted and achieved spherival equivalent in both groups. Additionally, a comparison between the groups of different IOL types was made using the one-way ANOVA in both groups. 


\section{Results}

In group 1 (Short ALs)

A total 38 eyes with short ALs from 29 patients were included in this group. The mean age of patients was $65.13 \pm 9.49$ year (range 41 to 80 ), the mean AL was $21.55 \pm 0.45 \mathrm{~mm}$ (range 20.05 to 21.99 ), the mean $\mathrm{K} 1$ was $45.76 \pm 1.77 \mathrm{D}$ (range 42.00 to 49.75 ), the mean K2 was $46.09 \pm 1.61 \mathrm{D}$ (range 41.87 to 48.25 ), the mean IOL power was $23.96 \pm 1.92 \mathrm{D}$ (range 21 to 30 ), the mean attempted preoperative spherical equivalent (attempted SE) was $0.07 \pm 0.26 \mathrm{D}$ (range -0.26 to 0.89 ), the mean achieved spherical equivalent (achieved SE) was $0.07 \pm 0.63 \mathrm{D}$ (range -1.0 to 1.50 ), the mean prediction error(PE) was $0.01 \pm 0.60 \mathrm{D}$ (range -1.015 to 1.060 ), the mean absolute error(MAE) was $0.51 \pm 0.31 \mathrm{D}$ (range 0.02 to 1.060$)$.

Pre-operative and demographic parameters are summarized in Table 1 and distribution of the prediction error (difference between attempted and achieved spherical equivalent) in eyes with short $\mathrm{AL}$ is shown in Table 2.

A statistically significant negative correlation was observed between AL and K1, K2, IOL power $(r=-0.442, p=$ $0.05 ; r=-0.461, p=0.04 ; r=-0.402, p=0.012$, respectively) (Fig. 1). A statistically significant positive correlation was found between MAE and IOL $\operatorname{power}(r=0.355, p=0.029)$ (Fig. 2). However, there was no significant correlation between MAE and AL, K1, K2, attempted SE or achieved SE. A statistically significant negative correlation was found between the mean PE and achieved SE $(r=-0.908$, $p=0.00$ ) (Fig. 2).

No statistically significant relationship was found between mean PE and the other parameters. A weak positive, but statistically insignificant linear relation was observed between attempted preoperative SE and achieved postoperative $\operatorname{SE}(r=0.289 ; p=0.078>0.05)$. There was no statistically significant difference between attempted preoperative

Table 1 Preoperative and demographic parameters in eyes with short and long AL

\begin{tabular}{|c|c|c|c|c|c|c|}
\hline & \multicolumn{3}{|l|}{ Short Eyes } & \multicolumn{3}{|l|}{ Long Eyes } \\
\hline & Range & Mean & SD & Range & Mean & SD \\
\hline Age(year) & $41-80$ & 65.13 & 9.49 & $38-80$ & 64.05 & 7.31 \\
\hline Axial length(mm) & $20.05-21.99$ & 21.55 & 0.45 & $24.60-32.90$ & 25.77 & 1.64 \\
\hline $\begin{array}{l}\text { Keratometry } \\
\mathrm{K}_{1}(\mathrm{D})\end{array}$ & $42.00-49.75$ & 45.76 & 1.77 & $39.25-45.25$ & 42.20 & 1.57 \\
\hline $\begin{array}{l}\text { Keratometry } \\
\mathrm{K}_{2}(\mathrm{D})\end{array}$ & $41.87-48.25$ & 46.09 & 1.61 & $39.62-46.00$ & 42.17 & 1.68 \\
\hline IOL power(D) & $21-30$ & 23.96 & 1.92 & $-5.00-(20.50)$ & 15.79 & 5.17 \\
\hline Gender & \multicolumn{3}{|c|}{$\begin{array}{l}6 \text { males }(20.69 \%)+23 \\
\text { females }(79.31 \%)\end{array}$} & \multicolumn{3}{|c|}{$\begin{array}{l}33 \text { males }(73.33 \%)+12 \\
\text { females }(26.67 \%)\end{array}$} \\
\hline Eye & \multicolumn{3}{|c|}{$\begin{array}{l}21 \text { right eyes }(55,3 \%) \\
+17 \text { left eyes }(44.7 \%)\end{array}$} & \multicolumn{3}{|c|}{$\begin{array}{l}30 \text { right eyes }(48.4 \%)+32 \\
\text { left eyes }(51.6 \%)\end{array}$} \\
\hline
\end{tabular}

Table 2 Distribution of the prediction error (difference between attempted and achieved spherical equivalent) in eyes with short and long AL using SRK/T formula and ultrasound biometry

\begin{tabular}{|c|c|c|c|c|}
\hline \multirow[t]{2}{*}{ Range of SE(D) } & \multicolumn{2}{|c|}{ Short Eyes } & \multicolumn{2}{|c|}{ Long Eyes } \\
\hline & $n$ & $\%$ & $n$ & $\%$ \\
\hline Within $\pm 0.25 \mathrm{D}$ & 10 & 26.32 & 14 & 22.58 \\
\hline Within $\pm 0.50 \mathrm{D}$ & 22 & 57.89 & 31 & 50.00 \\
\hline Within $\pm 1.0 \mathrm{D}$ & 36 & 94.74 & 44 & 70.97 \\
\hline $\begin{array}{l}>+1.0 \mathrm{D} \text { (more hyperopic } \\
\text { than predicted) }\end{array}$ & 1 & 2.63 & 3 & 4.84 \\
\hline$\geq+2.0$ & 0 & 0.00 & 2 & 3.23 \\
\hline $\begin{array}{l}<-1.0 \text { D (more myopic } \\
\text { than predicted) }\end{array}$ & 1 & 2.63 & 18 & 29.03 \\
\hline$\leq-2.0 \mathrm{D}$ & 0 & 0.00 & 3 & 4.84 \\
\hline
\end{tabular}

SE and achieved postoperative SE (Paired samples $t$ test; $t$ (37) $=-0.035, p=0.972>p=0.05)$

In the present study, three types of IOL were used in short eyes. The Softec 1 was used in 25 eyes (65.8\%), the Dr Schmidt in 8 eyes (21.0\%), and the Acriva IOL in 5 eyes (13.2\%). There was no relation-ship was detected between the PE and and the type of IOL $(p=0.631 ; p>0.05)$ in short eyes.

\section{In group 2 (Long ALs)}

There were 62 eyes of 45 patients (33 males, and 12 females). The mean age was $64.05 \pm 7.31$ year (range 38 to 80 ), the mean $\mathrm{AL}$ was $25.77 \pm 1.64 \mathrm{~mm}$ (range 24.60 to $32.90 \mathrm{D}$ ), the mean $\mathrm{K} 1$ was $42.20 \pm 1.57 \mathrm{D}$ (range; 39.25 to $45.25 \mathrm{D}$ ), the mean $\mathrm{K} 2$ was $42.17 \pm 1.68 \mathrm{D}$ (range 39.62 to $46.00 \mathrm{D}$ ), the mean IOL power was $15.79 \pm 5.17 \mathrm{D}$ (range $-5,00$ to $20.50 \mathrm{D})$, the mean attempted preoperative predictive spherical equivalent was $-0.434 \pm 0.315 \mathrm{D}$ (range -1.00 to $0.54 \mathrm{D})$, the achieved postoperative spherical equivalent was $-0.42 \pm 0.96 \mathrm{D}$ (range -2.62 to $2.75 \mathrm{D}$ ), the mean PE was $-0.004 \pm 0.93 \mathrm{D}$ (range -1.83 to $3.55 \mathrm{D}$ ), the MAE was $0.68 \pm 0.62 \mathrm{D}$ (range 0.005 to $3.55 \mathrm{D}$ ).

\section{Pre-operative and demographic parameters are shown in Table 1 and distribution of the prediction error in eyes with long $A L$ is shown in Table 2}

The Softec 1 IOL was used in 48 eyes (77. 4\%), the Dr Schmidt in 10 eyes (16.1\%), and the Acriva IOL was in 4 eyes $(6.5 \%)$

In present study, there was a statistically significant positive relationship between $\mathrm{AL}$ and $\mathrm{K} 1, \mathrm{~K} 2(r=0.432, p=0.00$ and $r=0.404, p=0.001$; respectively) (Fig. 3 ). A negative statistically significant strong relationship was found between $\mathrm{AL}$ and IOL power $(r=-0.867 p=0.00)$. No relationship was found between prediction and $\mathrm{AL}, \mathrm{K} 1, \mathrm{~K} 2$, IOLp, age. In addition, there was a strong positive correlation between $\mathrm{PE}$ and achieved postoperative $\mathrm{SE}(r=0.923$, 

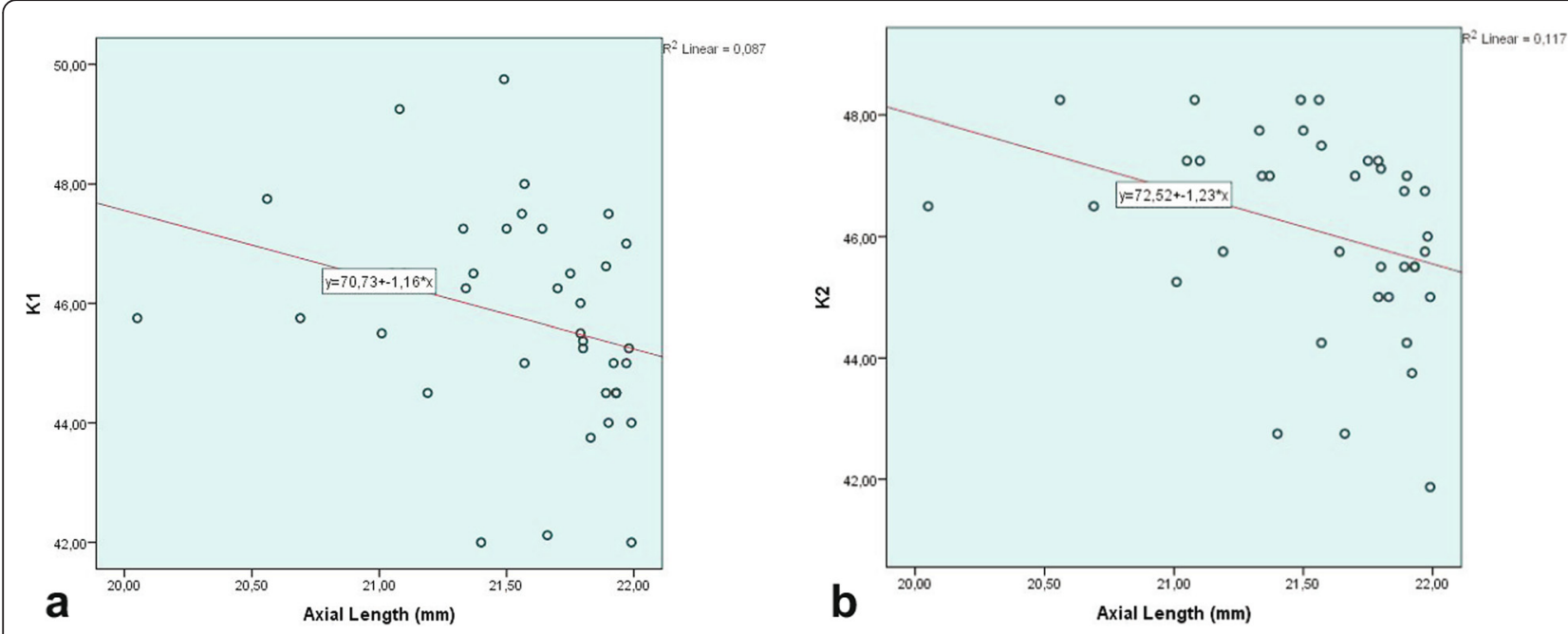

Fig. 1 Scatter plot of AL versus K1 (a) and K2 (b) in eyes with short ALs

$p=0.00)$ and no correlation with attempted preoperative SE (Fig. 4). There was a weak positive significant linear correlation between attempted preoperative SE and achieved postoperative $\mathrm{SE}(r=0.255 ; p=0.045)$ (Fig. 4). However, there was no significant difference in the values for attempted preoperative SE and achieved postoperative SE (Paired samples $t$ test; $t(61)=-0.105, p=0.917>p=0.05$ ). A strong negative relationship was found between IOL power and $\mathrm{K} 1$ and $\mathrm{K} 2(r=-0.710, p=0.00 ; r=-0.703$, $p=0.00$ respectively) (Fig. 3 )

No relation-ship was detected between the PE and the type of IOL $(p=0.501 ; p>0.05)$

\section{Discussion}

The SRK $\mathrm{T}$ formula is a third generation formula, described in 1990 by John Retzlaff, Kraff and Sanders [6].
This formula combines the benefits of both the theoretical and regression formula and uses the A-constant to calculate the ACD, using the retinal thickness and corneal refractive index. The ACD constant for SRK-T may be supplied by the manufacturer or may be calculated from the SRK-II [1, 3-6, 10-14, 16].

In the present retrospective study, we assessed the performance of the SRK/T formula using ultrasonic biometry in eyes with short and long ALs seperately.

\section{Group 1 (Short ALs)}

The AL is the most important factor in IOL calculation. Any measurement error in the AL of a short eye could have a larger effect on final refractive error. Compression of the eye is believed to be part of the cause of AL shortening error $[1-3,17,18]$. A mean shortening of
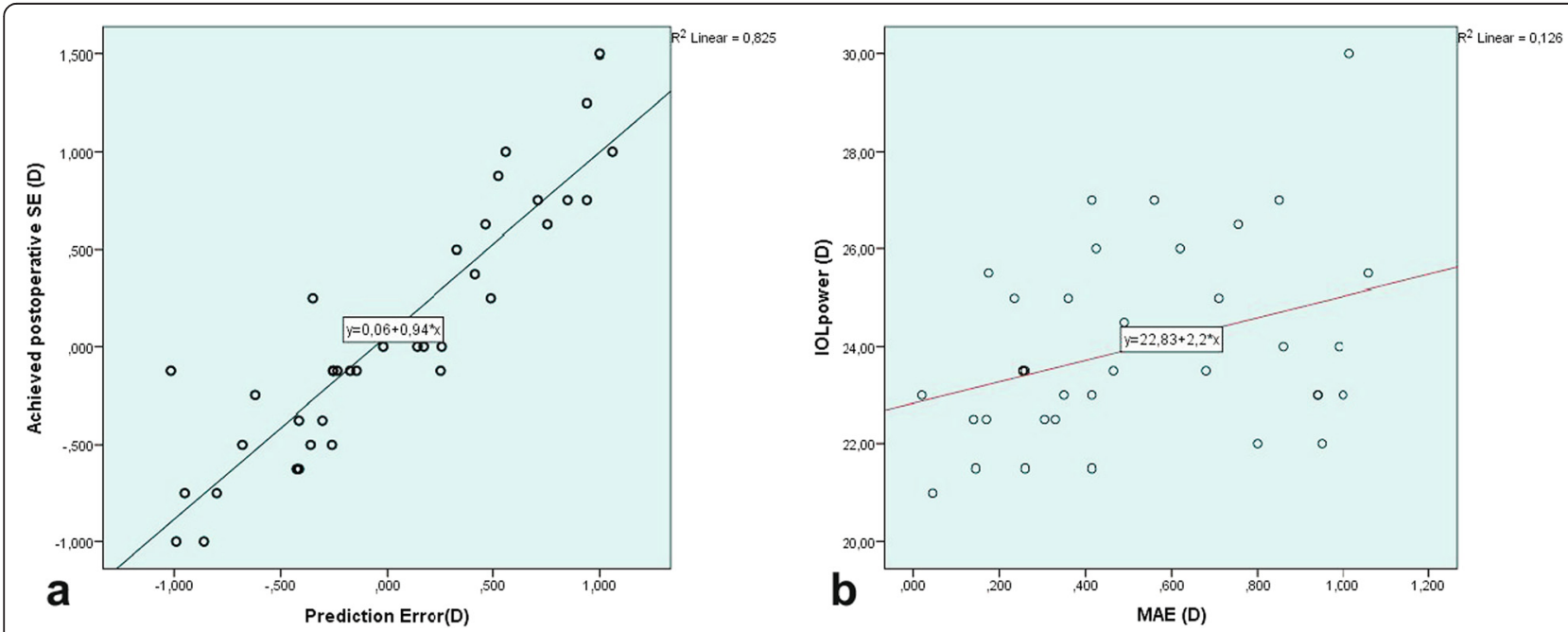

Fig. 2 Scatter plot of prediction error versus achieved SE (a) and MAE versus IOL power (b) in eyes with short ALs 

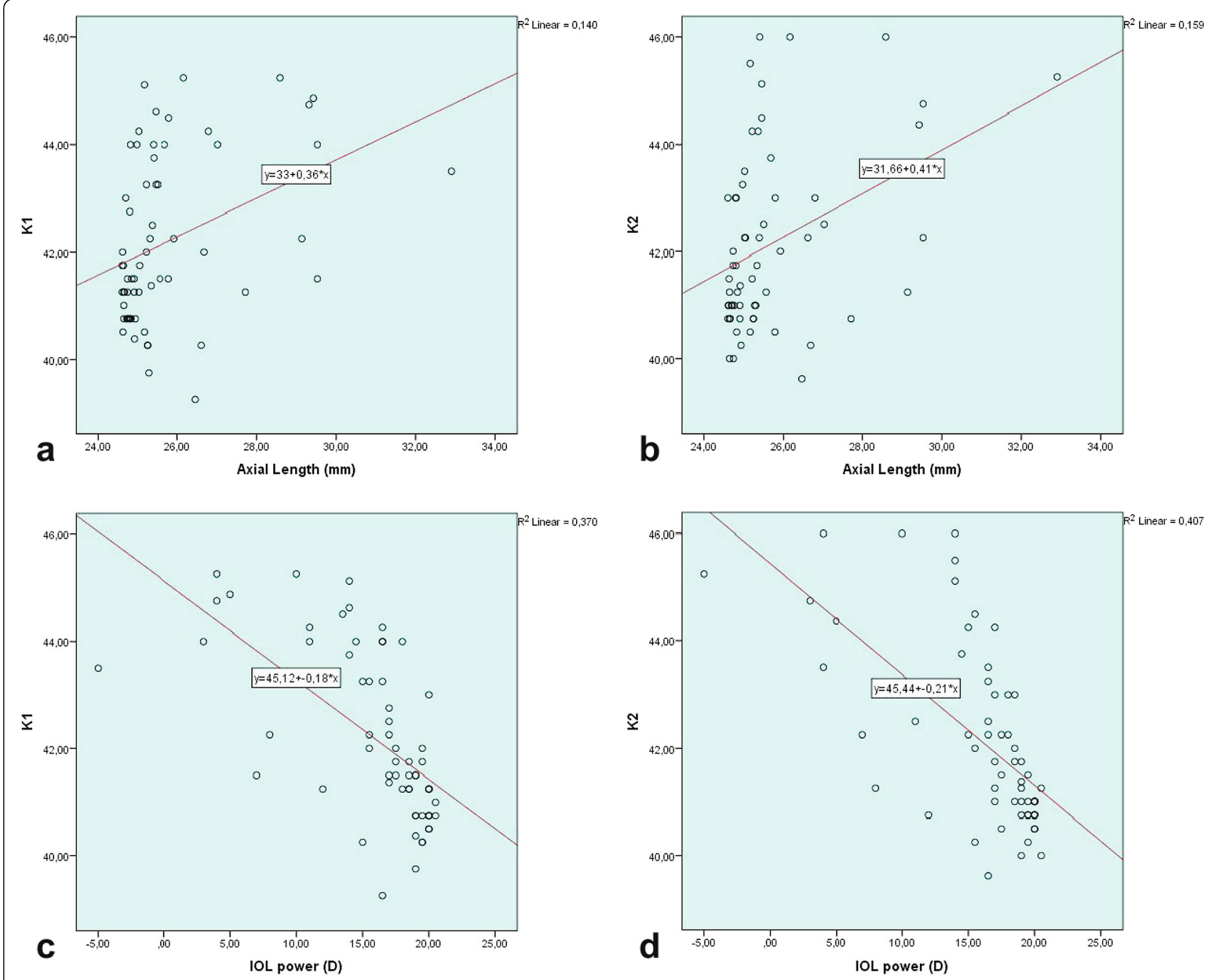

Fig. 3 Scatter plot of AL versus K1 (a), K2 (b), and IOL power versus K1 (c), K2 (d) in eyes with long ALs

$0.25-0.33 \mathrm{~mm}$ has been reported between applanation and immersion axial length measurements, which can translate into an error of IOL power by approximately 1 D [3, 17-19].

There are different studies to evaluate the predictive accuracy of various IOL power calculation formulas in eyes with short AL by using different IOL calculation methods and different results are reported. Sander et al. $[6,16]$ and Narvaez et al. [20] reported that the SRK/T effective and no difference between any of third and fourth generation formulas at errors. Wang et al. [21] showed that the SRK/T and Hoffer Q were equal. Gavin and Hammond [17], Aristodemou et al. [12], Kapadia et al. [22], Hoffer Q [5], Szaflik et al. [23], Day et al. [24] showed that the Hoffer Q formula more accurate, contrary to Maclaren et al. [25], Terzi et al. [26], Moschos et al. [27] and Roh et al. [18] reported that the Haigis formula was more accurate than the other formulas.
In our study, the mean PE was $0.017 \pm 0.58 \mathrm{D}$ (range from -1.060 to 1.015 ) and there was a little tendency towards hyperopia. We found a prediction accuracy of $57.89 \%$ for refractive errors of $\pm 0.50 \mathrm{D}$, a prediction accuracy of $94.74 \%$ for refractive errors of $\pm 1.00 \mathrm{D}$ using SRK/T in eyes with short ALs (Table 2). The MAE of our study was $0.48 \pm 0.29 \mathrm{D}$ (0.02 to 1.060 ). These results were similar to the previous studies or better than.

The ME was $0.87 \mathrm{D} \pm 0.829 \mathrm{D}$ with SRK/T formula in 41 eyes with $\mathrm{AL}<22.00 \mathrm{~mm}$ using IOL master(IOLm) in the study conducted by Gavin and Hammond [17], $0.834 \pm 0.262 \mathrm{D}$ in eyes with $\mathrm{AL}<22.00 \mathrm{~mm}(n=10$; relatively small size series) by Hoffer et al. [5], $0.53 \pm 0.25 \mathrm{D}$ in 25 eyes with $\mathrm{AL}<22.00 \mathrm{~mm}$ using IOLm by Roh et al.[18], $0.78 \pm 0.66 \mathrm{D}$ in 33 eyes with $\mathrm{AL}<22.00 \mathrm{~mm}$ using optical biometry by Wang et al. [21], $0.91 \pm 0.64 \mathrm{D}$ in 163 eyes with $\mathrm{AL}<22.00 \mathrm{~mm}$ using IOLm by Day et al., and $0.41 \pm$ $0.23 \mathrm{D}$ by Moschos et al. [27]. Contrary to the ME was $-1.45 \pm 0.14 \mathrm{D}$ in 76 eyes with mean $\mathrm{AL}=20.79 \mathrm{~mm}$ by 

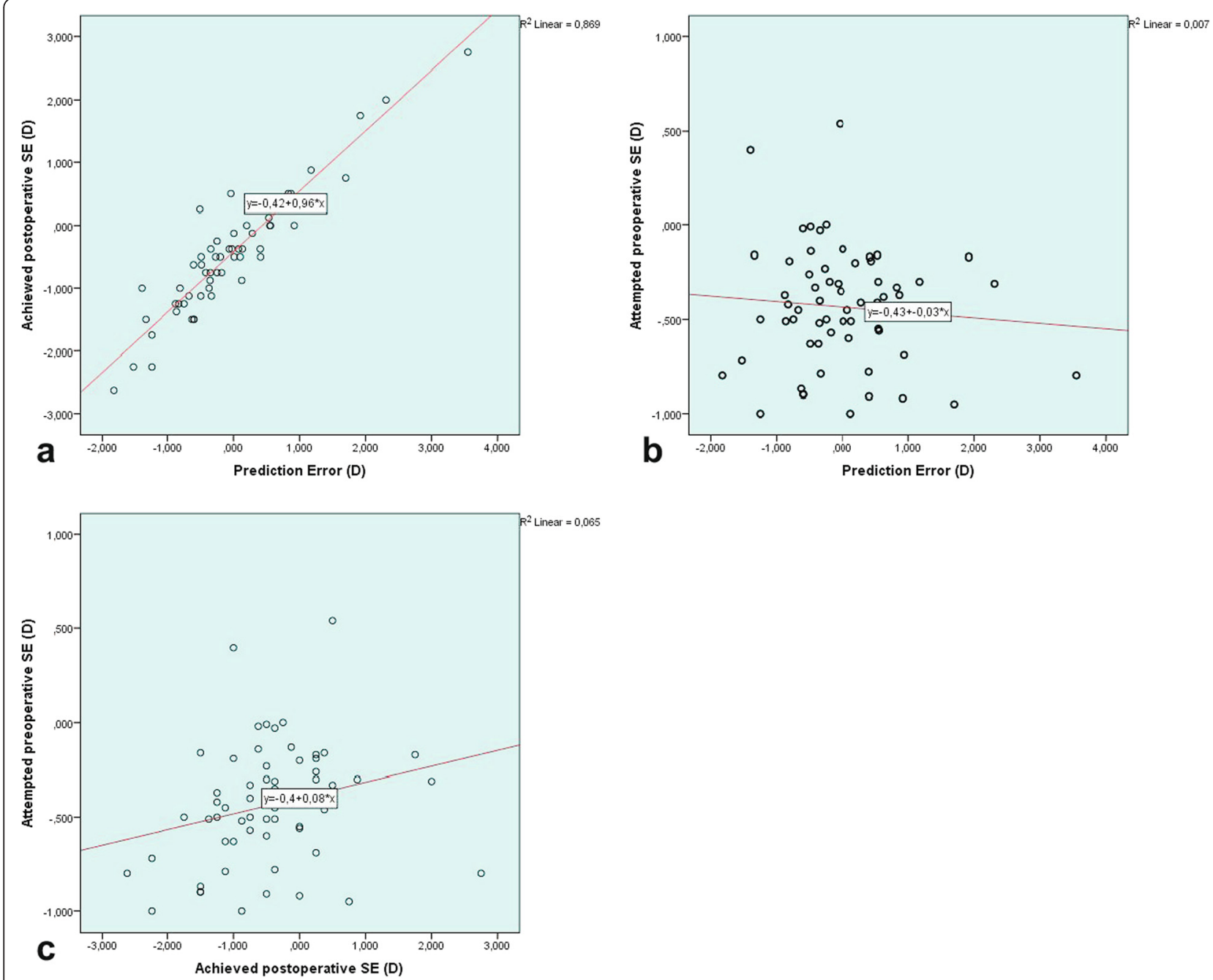

Fig. 4 Scatter plot of prediction error versus achieved SE (a), attempted SE (b) in eyes with long ALs and achieved SE versus attempted SE (c)

Maclaren et al. [25] and $-0.96 \pm-1.24 \mathrm{D}$ in eyes with axial length $<21,00 \mathrm{D}$ by Kapadia et al. [22]. Kapadia et al. reported that the postoperative SE within $\pm 1,0 \mathrm{D}$ was $80 \%$ with SRK/T formula using A-Scan biometry.

In this study, we found a negative correlation between AL and K1, K2, IOLp; practically, as AL decreased, K1, $\mathrm{K} 2$, and IOLp increased. A negative significiant correlation was found between PEand and achieved SE, but no correlation between PE and the other parameters.

\section{Groups 2 (Long ALs)}

The main difficulties in IOL power calculations for long eyes may be partly due to the anatomy of the posterior pole (posterior staphyloma). Posterior staphyloma decrease the accuracy of preoperative biometry. A-Scan biometry has a disadvantage compared with optic biometry and immersion biometry for accurate $\mathrm{AL}$ measurement [28-30]. Because of this, using A-Scan biometry with BScan mod together is recommended [29]. In our patients, sometimes A-Scan biometry was combined with B-Scan mod for detecting side of staphyloma.

The SRK/T formula probably the most accurate formula for long eyes and is now widely used. Holladay et al. [4], Sanders et al. [16],Hoffer Q [5], Kapadia et al. [22], Maclaren et al. [25], Donoso et al. [31], Kapamajian and Miller [32], Aristodemou et al. [12], El-Nafees et al. [33] and Chua et al. [34] were reported that SRK/T formula was more accurate than the other formulas in long eyes. Haigis et al. [15, 35], Terzi et al. [26], Bang et al. [36] and Roessler et al. [30] reported that the Haigis formula more accurate than the SRK/T formula and the others. Mitra et al. [37] and Petermeier et al. [38] reported that the SRK/T, Haigis or; Holliday were equal. Wang et al. [39] reported that the SRK/T and Haigis formula were comparable.

Sanders et al. [16] reported that for errors less than 0.5D was $45 \%$, less than $1.0 \mathrm{D}$ the results was $85 \%$, and greater than $2 \mathrm{D}$ was $2.5 \%$ by the SRK/T formula. In that study, 
there was no difference between SRK/T formula and the others. In the study conducted by Petermeier et al. [38], postoperative SE was $-1.42 \pm 1.33 \mathrm{D}(-3.94$ to +1.0$)$ (positive dioptre IOL group $(n=30)$ and postoperative SE was within $\pm 0.5 \mathrm{D}$ in $45.5 \%$ of cases, and within $\pm 1.0 \mathrm{D}$ in $77.3 \%$ of cases. Zaldivar et al. [29] reported that 92\%of eyes were within $\pm 1.0 \mathrm{D}$ when using SRK/T formula in cases of plus power IOLs, and $54 \%$ with the SRK/T in the cases of minus power IOLs. Maclaren et al. [25] did a retrospective analysis in 75 eyes having cataract surgery with zero- or negative-powered IOLs using SRK/T formula and A-scan, B-scan, and optic biometry. They also reported that forty-one percent of 75 patients analyzed were within $\pm 1.00 \mathrm{D}$ of the predicted refraction and $95 \%$ confidence interval, 0.89-1.39 D. Kapadia et al. [22] reported that the MAE $-0.59 \pm 0.91 \mathrm{D},-0.46 \pm 0.24 \mathrm{D}, 0.24$ $\pm-0.05 \mathrm{D}$ in eyes with axial length $24-27 \mathrm{~mm}(n=28)$, $27-29 \mathrm{~mm}(n=27)$, and $>29 \mathrm{~mm}(n=25)$ respectively, using SRK/T formula and A-Scan biometry. The postoperative $\mathrm{SE}$ was within $\pm 1 \mathrm{D}$ in $67.85 \%$ of cases when using SRK/T formula (Haigis equall; $68 \%$ ) in their study.

Ghanem and El-Sayed [28] reported that the postoperative SE was $\pm 1.0 \mathrm{D}$ of assumed refraction in $75 \%$, the refractive outcome was within $\pm 1.0 \mathrm{D}$ in $45 \%$, and there was a tendency toward hyperopia with SRK/T formula $(n=$ $127, \mathrm{AL} \geq 26 \mathrm{~mm}$ ). In the study conducted by Holladay et al. $[4,7]$, the ME was $-0.194 \mathrm{D}$, and the MAE was $0.345 \pm$ $0.401 \mathrm{D}$ in eyes with AL 24.5-26.0 mm, the ME was 0.041, the MAE was $0.442 \pm 0.56 \mathrm{D}$ in eyes with AL greater than 26.0, and the MAE was $0.38 \pm 0.47 \mathrm{D}$ in all long eye. In a study consisting of more than 300 long eyes, Aristodemou et al. [12] reported that the SRK/T had the lowest MAE, with statistically significant differences for ALs of $27.00 \mathrm{~mm}$ or longer. Mitra et al. [37] found the ME was +0.92 D with SRK/T formula using applanation ultrasonography in Indian myopic population with long axial lengths (24.75$32.35 \mathrm{~mm})$. Wang et al. [39] reported that the MAE was $0.45 \pm 0.10 \mathrm{D}$ with the SRK formula in eyes with AL more than $26 \mathrm{~mm}(n=75)$. Narvaez et al. [20] reported the MAE was $0.49 \pm 0.39(0.00 \pm 2.26 \mathrm{D} ; 24.5-26.0 \mathrm{~mm})$, the MAE was $0.55 \pm 0.64 \mathrm{D}$ (range $0.04 \pm 3.48 \mathrm{D}$; greater than $26 \mathrm{~mm}$ ) in totally 181 eyes. El Nafees et al. [33] reported that the ME was +0.04 D (25-27 mm), +0.15D (27$29 \mathrm{~mm}),+0.33 \mathrm{D}(29-31.4 \mathrm{~mm})$ with SRK/T and the MAE was less than 1.0D in $81.3 \%$ eyes ( $n=53$ eyes). Chua et al. [34] reported that the ME was $0.18 \mathrm{D}$ for eyes using SRK/T with ALs greater than $25 \mathrm{~mm}$, Kapamajian and Miller [32] reported the mean PE was +1.16D and Roessler et al. [30] reported the MAE was $1.01 \pm 0.61 \mathrm{D}$ with the SRK/T formula using optical biometry in long eyes.

In our study, the mean AL was $25.77 \mathrm{D}$ (range from 24.60 to 32.90 ) and the mean IOLp was 15.80 (range from -5.00 to $20.50 \mathrm{D}$ ). Only one patient had a negative IOL power. The postoperative SE was $0.42 \pm 0.96 \mathrm{D}$ (range; -2.62 to $2.75 \mathrm{D}$ ), within $\pm 1 \mathrm{D}$ in $70.97 \%$ of cases and within $\pm 0.5 \mathrm{D}$ in $50 \%$ of cases. The mean PE of in long ALs was $-0.004 \pm 0.93 \mathrm{D}$ (range from $-1.83 \mathrm{D}$ to 3.55D) and there was a little tendency towards myopia. The MAE was $0.68 \pm 0.62 \mathrm{D}$ (range 0.005 to $3.55 \mathrm{D}$ ). We showed a prediction accuracy of $50 \%$ for refractive errors of $\pm 0.50 \mathrm{D}$, a prediction accuracy of $70.97 \%$ for refractive errors of $\pm 1.00 \mathrm{D}$ using SRK/T formula in eyes with long ALs (Table 2). We found a positive significant relationship between attempted preoperative $\mathrm{SE}$ and achieved postoperative SE $(r=0.255 ; p=0.045)$. These results showed that refractive outcomes similar to the preoperative target refractive prediction $\pm 1 \mathrm{D}$ were reached. Only a few refractive surprises may be due to the AL errors in ultrasonic biometry or use of inappropriate formula.

Additionaly, the other results of our study can be summarized as follows:

1. We found no significant relation-ship between PE and AL,K1,K2, IOLp, IOL types, age in both groups.

2. We found a significant negative correlation for short ALs, contrary to a significant positive correlation for long ALs, between PE and achieved SE.

3. We found no significant relation-ship was found between MAE and AL, K1, K2, age, attempted SE, achieved SE in both groups.

4. We found a significant negative correlation between $\mathrm{AL}$ and $\mathrm{K} 1, \mathrm{~K} 2$, IOLp in short ALs, a significant positive correlation between AL and $\mathrm{K} 1, \mathrm{~K} 2$, contrary to negative AL and IOLp in long ALs.

This study has some weakness. Firstly, it is a retrospective analysis. Secondly, the relatively sample size (38 eyes) and a narrow range (20.50-21.99 D) of AL for the short eyes. Thirdly, only one formula(SRK/T) was used for IOL calculation and not compared with other formulas. Finally, different IOL types and IOL constants were used. On the other hand, our study also has some strength. Firstly, all surgeries and procedures were performed by a single surgeon with the same technique and devices. Secondly, relatively large sample size for long eyes $(n=62)$. Finally, using only one formula, the SRK/T formula, is an advantage of this study so as to determine the performance of a single formula.

\section{Conclusion}

The results of the present study indicate that the SRK/T formula works well accurately in eyes with short and long ALs and shows a little tendency towards hyperopia for short, and myopia for long ALs. Further studies are needed to evaluate the performance of SRK/T formula in a wider range of eyes for short and long ALs. Additionally, this study suggests that the unexpected or unpredicted 
refractive outcome may happen. For this reason, ultrasonic biometry should be done carefully by an expert.

\section{Abbreviations}

AL(s), axial length(s); IOL, intraocular lens; IOLm, IOL master; IOLp, intraocular lens power; $K$, keratometry value; $M A E$, mean absolute error; $M E$, mean (prediction) error; $\mathrm{PCl}$, partial coherence interferometer; $\mathrm{PE}$, prediction error; $\mathrm{SD}$, standard deviation; SE, spherical equivalent; US, ultrasound

\section{Acknowledgements}

None.

\section{Funding}

This study was not supported by any funding project.

\section{Availability of data and materials}

The dataset supporting the conclusions of this article is included within the article.

\section{Authors' contributions}

Design, conception and conduct of the study (YK, ME), literature screening and selection (YK, FK, ME), data collection (YK, FK), management (YK, ME, FK), acquisition of data or performing statistical analysis and interpretation of the data (YK, ME), preparation and review (YK, FK, ME). All authors read and approved the final manuscript.

\section{Competing interests}

The authors declare that they have no competing interests.

\section{Consent for publication}

Not applicable

\section{Ethics approval and consent to participate}

The study was approved by the Ethical Committee of the Istanbul Medipol University (Approval date and number 2015/347) and was conducted in accordance with the Declaration of Helsinki. Written and informed consent was obtained from all patients.

\section{Author details}

${ }^{1}$ Department of Ophthalmology, Istanbul Medipol University, Esenler Hospital, Birlik Mah., Bahceler Cad., Number 5, Esenler, Istanbul 34230, Turkey. ${ }^{2}$ Department of Ophthalmology, School of Medicine, Istanbul Medipol University, Kadıkoy Medipol Hospital, Lambaci Sokak Number 1, Kosuyolu, Kadikoy, Istanbul 34718, Turkey.

Received: 22 November 2015 Accepted: 9 June 2016

Published online: 08 July 2016

\section{References}

1. Kaswin G, Rousseau A, Mgarrech M, Barreau E, Labetoulle M. Biometry and intraocular lens power calculation results with a new optical biometry device: comparison with the gold standard. J Cataract Refract Surg. 2014;40(4):593-600.

2. Hope-Ross M, Mooney D. Intraocular lens power calculation. Eye (Lond). 1988;2(4):367-9.

3. Olsen T. Calculation of intraocular lens power: a review. Acta Ophthalmolscand. 2007:85(5):472-85.

4. Holladay JT, Prager TC, Chandler TY, Musgrove KH, Lewis JW, Ruiz RS. A three-part system for refining intraocular lens power calculations. I Cataract Refract Surg. 1988;14(1):17-24.

5. Hoffer KJ. The Hoffer Q formula: a comparison of theoretic and regression formulas. J Cataract Refract Surg. 1993;19(6):700-12

6. Retzlaff J, Sanders DR, Kraff MC. Development of the SRK/T intraocular lens implantation power calculation formula. J Cataract Refract Surg. 1990:16(3):333-40

7. Holladay JT. Standardizing constants for ultrasonic biometry, keratometry, and intraocular lens power calculations. J Cataract Refract Surg. 1997;23(9):1356-70.

8. Haigis W. The Haigis formula. In: Shammas HJ, editor. Intraocular Lens Power Calculations. Thorofare: Slack; 2004. p. 41-57.
9. Olsen T, Thim K, Corydon L. Accuracy of the newer generation intraocular lens power calculation formulas in long and short eyes. J Cataract Refract Surg. 1991;17:187-93.

10. Findle O. Biometry and intraocular lens power calculation. Curr Opin Ophthalmol. 2005;16(1):61-1.

11. Rose LT, Moshegov CN. Comparison of the Zeiss IOLMaster and Applanation A-Scan ultrasound: biometry for intraocular lens calculation. Clin Exp Ophthalmol. 2003;31(2):121-4.

12. Aristodemou P, Knox Cartwright NE, Sparrow JM, Johnston RL. Formula choice: Hoffer Q, Holladay 1, or SRK T, and refractive outcomes in 8108 eyes after cataract surgery with biometry by partial coherence interferometry. J Cataract Refract Surg. 2011;37(1):63-71.

13. Fontes BM, Fontes BM, Castro E. Intraocular lens power calculation by measuring axial length with partial optical coherence and ultrasonic biometry. Ara Bras Oftalmol. 2011;74(3):166-70.

14. Findl O, Kriechbaum K, Sacu S, Kiss B, Polak K, Nepp J, Schild G, Rainer G, Maca S, Petternel V, Lackner B, Drexler W. Influence of operator experience on the performance of ultrasound biometry compared to optical biometry before cataract surgery. J Cataract Refract Surg. 2003;29(10):1950-5.

15. Haigis W, Lege B, Miller N, Schneider B. Comparison of immersion ultrasound biometry and partial coherence interferometry for intraocular lens calculation according to Haigis. Graefe's Arch Clin Exp Ophthalmol. 2000;238(9):765-73.

16. Sanders DR, Retzlaff JA, Kraff MC, Gimbel HV, Raanan M. Comparison of the SRK $T$ formula and other theoretical and regression formulas. J Cataract Refract Surg. 1990;16(3):341-6.

17. Gavin EA, Hammond CJ. Intraocular lens power calculation in short eyes. Eye(Lond). 2008;22(7):935-8.

18. Roh YR, Lee SM, Han YK, Kim MK, Wee WR, Lee JH. Intraocular lens power calculation using IOLMaster and various formulas in short eyes. Korean $J$ Ophthalmol. 2011:25(3):151-5.

19. Lee AC, Qazi MA, Pepose JS. Biometry and intraocular lens power calculation. Curr Opin Ophthalmol. 2008;19(1):13-7.

20. Narváez J, Zimmerman G, Stulting RD, Chang DH. Accuracy of intraocular lens power prediction using the Hoffer Q, Holladay 1, Holladay 2, and SRKT formulas. J Cataract Refract Surg. 2006;32(12):2050-3.

21. Wang JK, Chang SW. Optical biometry intraocular lens power calculation using different formulas in patients with different axial lengths. Int J Ophthalmol. 2013:6(2):150-4.

22. Kapadia P, Dalal N, Patel N, Chauhan MD. Intraocular lens power calculation formulas in high refractive errors, what to choose and when? NJIRM. 2013:4(3):33-6

23. Szaflik J, Kamińska A, Gajda S, Jedruch A. Accuracy of the SRK II, SRKT, Holladay and Hoffer Q IOL power calculation formulas in hyperopic patients after phacoemulsification. Klin Oczna. 2005;107(10-12):615-9. Polish.

24. Day AC, Foster PJ, Stevens JD. Accuracy of intraocular lens power calculations in eyes with axial length $<22.00 \mathrm{~mm}$. Clin Experiment Ophthalmol. 2012:40(9):855-62.

25. Maclaren RE, Natkunarajah M, Riaz Y, Bourne RR, Restori M, Allan BS. Biometry and formula accuracy with intraocular lenses used for cataract surgery in extreme hyperopia. Am J Ophthalmol. 2007;143(6):920-31.

26. Terzi E, Wang L, Kohnen T. Accuracy of modern intraocular lens power calculation formulas in refractive lens exchange for high myopia and high hyperopia. J Cataract Refract Surg. 2009:35(7):1181-9.

27. Moschos MM, Chatziralli IP, Koutsandrea C. Intraocular lens power calculation in eyes with short axial length. Indian J Ophthalmol. 2014;62(6):692-4

28. Ghanem AA, El-Sayed HM. Accuracy of intraocular lens power calculation in high myopia. Oman J Ophthalmol. 2010;3(3):126-30

29. Zaldivar R, Mitchell C, Holladay JT. Intraocular lens power calculations in patients with extreme myopia. J Cataract Refract Surg. 2000;26:668-74

30. Roessler GF, Dietlein TS, Plange N, Roepke AK, Dinslage S, Walter P, Mazinan BA. Accuracy of intraocular lens power calculation using partial coherence interferometry in patients with high myopia. Ophthalmic Physiol Opt. 2012;32(3):228-33

31. Donoso R, Mura JJ, Lopez M. Emmetropization at cataract surgery. Looking for the best IOL power calculation formula according to the eye axial length. Arch Soc Esp Oftalmol. 2003;78:477-80 
32. Kapamajian MA, Miller KM. Efficacy and safety of cataract extraction with negative power intraocular lens implantation. Open Ophthalmol J. 2008;15(2):15-9.

33. El-Nafees R, Moawad A, Kishk H, Gaafar W. Intra-ocular lens power calculation in patients with high axial myopia before cataract surgery. Saudi J Ophthalmol. 2010;24(3):77-80.

34. Chua WH, Lee MW, Chan YH, et al. Prospective comparison of different formulae for calculating IOL power in Asian eyes with long axial lengths. Stockholm: XXIV Congress of the ESCRS; 2007.

35. Haigis W. Intraocular lens calculation in extreme myopia. J Cataract Refract Surg. 2009:35(5):906-11.

36. Bang S, Edell E, Yu Q, Pratzer K, Stark W. Accuracy of intraocular lens calculations using the IOLMaster in eyes with long axial length and a comparison of various formulas. Ophthalmology. 2011;118(3):503-6.

37. Mitra A, Jain E, Sen A, Tripathi S. A study regarding efficacy of various intraocular lens power calculation formulas in a subset of Indian myopic population. Indian J Ophthalmol. 2014:62(7):826-8.

38. Petermeier K, Gekeler F, Messias A, Spitzer MS, Haigis W, Szurman P. Intraocular lens power calculation and optimized constants for highly myopic eyes. J Cataract Refract Surg. 2009;35(9):1575-81.

39. Wang JK, Hu CY, Chang SW. Intraocular lens power calculation using the IOLMaster and various formulas in eyes with long axial length. J Cataract Refract Surg. 2008;34(2):262-7.

\section{Submit your next manuscript to BioMed Central} and we will help you at every step:

- We accept pre-submission inquiries

- Our selector tool helps you to find the most relevant journal

- We provide round the clock customer support

- Convenient online submission

- Thorough peer review

- Inclusion in PubMed and all major indexing services

- Maximum visibility for your research

Submit your manuscript at www.biomedcentral.com/submit 